\title{
Construção valorativa de fatos sociais: a multiplicidade de discursos
}

\author{
Evaluative construction of social facts: the multiplicity of discourses
}

\author{
Cláudio Primo Delanoy ${ }^{1}$ \\ Tamiris Machado Gonçalves² \\ Vanessa Fonseca Barbosa ${ }^{3}$ \\ Pontifícia Universidade Católica do Rio Grande do Sul - PUCRS - Rio Grande do Sul - Brasil
}

\begin{abstract}
Resumo: O presente artigo tem o objetivo de compreender o funcionamento do discurso instaurado a partir do entendimento das relações dialógicas que se dão entre o fato de uma charge polêmica ter sido exposta na sala de um juiz e a repercussão desse caso por um político brasileiro. A partir da análise de três postagens de três blogues diferentes referentes ao acontecimento, busca-se a construção discursiva dos fatos sociais frente à tensão de vozes que envolve a constituição dos sentidos em circulação. Espera-se, ao longo do desenvolvimento do texto, explorar os conceitos de discurso, valor e vozes sociais advindos dos pressupostos teóricos de Bakhtin e seu Círculo de estudos, teoria que ancora as reflexões propostas neste artigo.
\end{abstract}

Palavras-chave: Teoria bakhtiniana; Discurso; Valoração; Vozes sociais

\begin{abstract}
This article aims to understand the functioning of discourse brought from the understanding of the dialogic relations that exist between the fact of a cartoon controversy have been exposed in the room of a judge and the impact of this case by a Brazilian politician. From the analysis of three posts in three different blogs for the event, the discursive construction is sought of social facts opposite voltage voices that involves the formation of the senses in circulation. Hopefully, throughout the text of development, explore the discourse of concepts, value and social voices arising from the theoretical assumptions of Bakhtin and his Circle studies, theory that anchors the reflections proposed in this paper.
\end{abstract}

Keywords: Bakhtinian theory; Discourse; Valuation; Social voices

\section{Considerações iniciais}

A linguagem é um dos elementos mais marcantes da cultura de uma sociedade. Através da linguagem, o homem estabelece trocas e valores simbólicos que possibilitam variadas relações. É por meio da linguagem, de modo geral, que se dá a criação e propagação do pensamento abstrato, de conceitos, valores e fatos que constituem a história da humanidade. Sabe-se, no entanto, que compreender esse objeto não costuma ser simples, pois a linguagem é um fenômeno complexo, que requer diferentes pontos de vista para ser contemplado em sua dinâmica.

Assim, muitos pensadores e diversas correntes teóricas, sobretudo aquelas vinculadas às pesquisas linguísticas, têm buscado, ao longo do tempo, melhor compreender e explicar esse objeto de natureza multifacetada. Alguns desses estudos centram-se na linguagem como fenômeno abstrato e defendem que ela deve ser apreendida do modo mais objetivo possível; outros têm por ponto de partida a linguagem em uso, procurando entender o estabelecimento de sentidos

\footnotetext{
1 Professor do Programa de Pós-graduação em Letras da PUCRS.

2 Aluna de doutorado no curso de Pós-graduação em Letras, área de concentração em Linguística da PUCRS. Bolsista CNPq.

3 Aluna de doutorado no curso de Pós-graduação em Letras, área de concentração em Linguística, da PUCRS. Bolsista CNPq.
} 
instaurados nas mais diversas situações enunciativas. Este é o caso, por exemplo, dos estudos de Bakhtin e seu Círculo que, com vistas a compreender a dinamicidade da linguagem, propõem um método sociológico que toma como centro o discurso - entendido como enunciação viva, oriunda de situações concretas de interação entre sujeitos social e historicamente localizados - e preconiza que a enunciação deve ser estudada como um todo de sentido, de onde os pesquisadores haurem os fatos da língua.

Para tanto, orienta essa vertente de pensamento que os signos ideológicos, em sua realidade material, não devem ser separados de sua ideologia; não devem ser dissociados das formas concretas de comunicação de onde emergem; tampouco se deve abstrair a comunicação e suas formas de sua infraestrutura, isto é, sua base material (BAKTHIN/VOLOCHÍNOV ${ }^{4}$ [1929] 2009, p. 45). Essas considerações, de modo geral, pretendem afastar os estudos da linguagem de teorias abstratas que recortam os problemas da linguagem como objetos separados de sua natureza social, reduzindo-os a fatos apenas linguísticos.

Nas mais diversas práticas da atividade humana, o discurso, conforme as ideias de Bakhtin, em o Dicionário de Enunciação, é entendido como fenômeno multifacetado, originado, pois, do diálogo entre as diversas enunciações que se constituem no meio social e o compõem. Dessa maneira, o discurso é tomado como dialógico por natureza, isto é, edifica-se meio a já-ditos e projeta, ao mesmo tempo, discursos outros que surgem como resposta a ele. É nesse sentido que a teoria expressa que todo discurso está tecido por uma heterogeneidade de vozes, resultantes de interações sociais complexas (cf. DI FANTI, 2009, p. 84).

Nessa perspectiva, compreende-se que o discurso traz consigo a multiplicidade de vozes que o constituem a partir das diferentes experiências vividas pelos sujeitos ao longo da história. Como a realidade não é reflexo direto da vida, a linguagem constrói discursivamente os fatos sociais e deixa entrever, a partir dos signos ideológicos, as apreciações valorativas do locutor sobre o mundo.

Com efeito, no discurso não há neutralidade. Os signos ideológicos, as palavras, os enunciados são sempre orientados de maneira valorativa. Bakhtin/Volochínov ([1929] 2009. p. 32) afirma que todo o signo está sujeito à avaliação ideológica, ou seja, à análise no intuito de compreender se algo é verdadeiro, correto, justificável,

\footnotetext{
4 Não entramos na discussão acerca da autoria dos textos considerados disputados. Assim sendo, citamos os nomes conforme as referências consultadas apresentam. No caso de Marxismo e filosofia da linguagem, por exemplo, temos um autor, mas a menção de dois nomes, por isso Bakhtin/Volochínov. Como a questão autoral discute se um ou outro é o autor, não acreditando em dupla autoria, os verbos são colocados no singular - a julgar pela própria apresentação do livro feita por Roman Jakobson que traz verbos no singular.
}

falso, errôneo. O autor diz ainda que o "domínio do ideológico coincide com o domínio dos signos" (p. 33). Assim, aquilo que é ideológico é também semiótico.

Tratar de questões que contemplam a análise do funcionamento do discurso, vislumbrando compreender sua construção valorativa, tem norteado muitas pesquisas linguísticas, tal como a que se desenvolverá neste artigo, que tem por objetivo compreender como se dá, no discurso, a construção de sentidos instaurados a partir do entendimento das relações dialógicas que se constituem entre o fato de uma charge polêmica ter sido exposta por um juiz e a repercussão desse caso por um político brasileiro. O episódio que desencadeou o embate de vozes foi veiculado pela mídia nacional no ano de 2013, resultando em matérias em jornais e páginas na internet. A partir da análise de três postagens de três blogues diferentes, referentes ao acontecimento, buscase demonstrar como ocorreu a construção discursiva dos fatos sociais frente à tensão de vozes que envolve a constituição dos sentidos em circulação.

O interesse pela temática apresentada advém da necessidade de compreender como se dá a construção do sentido na e pela linguagem. Ademais, é oportuno observar como os fatos são construídos discursivamente, quais efeitos de sentido proporcionam e como o gênero postagem de blogue movimenta recursos para, meio a aparente opacidade da linguagem, construir o objeto a que se refere (seu tema), com base no interlocutor projetado, na orientação social que se tem dele a partir do caráter emotivo-volitivo que dá o tom da situação em questão.

Para tanto, este trabalho ancorar-se-á em postulados do Círculo de Bakhtin, tais como: gêneros do discurso, signo ideológico, relações dialógicas, discurso e valoração. Além disso, a teoria em questão contribui com a fundamentação teórica deste artigo porque outorga elementos, em perspectiva interdisciplinar, sobre "a linguagem em uso, artístico ou cotidiano, sobre as relações constitutivas existentes entre linguagem, sujeitos, sociedades, culturas" (BRAIT, in: MEDVIÉDV, [1928] 2012).

Cabe mencionar ainda como está organizado o presente artigo: as palavras iniciais desta introdução serão seguidas por uma seção que discorre sobre os conceitoschave da teoria de Bakhtin e seu Círculo de estudos relevantes para a discussão dos objetivos delineados. $\mathrm{Na}$ sequência, será realizada uma análise de três postagens de diferentes blogues a fim de que se possa refletir acerca da construção valorativa dos fatos sociais. Por fim, serão expostas as considerações que encerram o presente texto, as quais não esgotam o tema, mas marcam o acabamento necessário para delinear o fecho deste artigo e possibilitar a atitude responsiva dos interlocutores deste trabalho. 


\section{Círculo de bakhtin: visão enunciativo-discursiva da linguagem}

$\mathrm{O}$ que denominamos de pensamento bakhtiniano são os estudos advindos do chamado Círculo de Bakhtin composto, segundo Faraco (2009, p. 13), por intelectuais que se reuniram regularmente de 1919 a 1929 na Rússia. Constituído por pensadores com diferentes formações e interesses, o resultado foi um grupo multidisciplinar. Os integrantes mais conhecidos são Mikhail M. Bakhtin, Valentin N. Volochínov e Pavel N. Medvedev.

Devido à seleção do objeto deste texto, nesta seção, iniciar-se-á a reflexão sobre os princípios teóricos de Bakhtin e seu Círculo a partir do conceito de gêneros discursivos e de seus elementos constitutivos; após, tratar-se-á dos conceitos de discurso, bem como o de valoração e o de relações dialógicas. Cabe fazer uma ressalva para o fato de que não se deve compreendê-los isoladamente. Uma vez que significam na dinâmica de sua inter-relação, a sistematização da exposição dos conceitos é fundamental apenas para fins de estudo e didatização.

No ensaio Gêneros do discurso, em Estética da criação verbal, de modo mais sistemático, Bakhtin fala sobre os gêneros discursivos. De acordo com o autor ([1979] 2011, p. 262), gêneros discursivos são "tipos relativamente estáveis de enunciados" que apresentam conteúdo temático, estilo e composição própria. Todos esses aspectos estão interligados e conectados ao todo do enunciado, sendo determinados pela esfera de comunicação discursiva de onde emergem.

Assim, em cada período da história e em cada comunidade social há um conjunto de formas de discurso na comunicação (BAKHTIN/VOLOCHÍNOV ([1929] 2009, p. 44). Como pode-se perceber, a noção de gêneros está intrinsecamente localizada no cerne da teoria bakhtiniana no sentido de que o enunciado é social, nasce e se desenvolve no discurso, a partir das relações socioideológicas que se dão entre sujeitos situados em um tempo e espaço definidos.

Os gêneros, pois, fazem parte do sistema cultural, "nos são dados quase da mesma forma que nos é dada a língua materna" (BAKHTIN, [1979] 2011, p. 282). Nesse sentido, eles são mais que forma, são construções comunicativas com as quais o sujeito interage desde sempre. São composições dinâmicas vinculadas às atividades sociais em que o sujeito está inserido. Os gêneros do discurso são um padrão sociodiscursivo com funções específicas de comunicação dentro de determinado campo da atividade humana, ou seja, no âmbito de uma esfera discursiva que está ligada às praticas sociais que nela se desenvolvem.

Nessa perspectiva, pensando no objeto que é foco desta discussão, pode-se afirmar que o gênero postagem de blogue possui uma forma composicional dinâmica por estar baseado em um conceito de comunicação rápida, trazido com a invenção da internet, em que quem informa primeiro tem maior visibilidade. Outra questão é que a internet constitui-se como um ambiente de livre exibição, onde todos podem criar páginas virtuais - os chamados weblog (registro na web) que deram origem aos blogues, registros na internet, que possibilitam a exposição de qualquer tipo de materiais como textos, fotos, montagens tanto de caráter pessoal (assim tem-se o blogue como diário virtual) quanto de assuntos públicos, veiculados por outros sites (sendo necessário informar a fonte da divulgação).

Se quanto ao conteúdo temático o blogue é uma cesta de variedades, no que tange à sua estrutura composicional também o é. As postagens podem ter diferentes estruturas: diário pessoal, reflexão sobre temas da atualidade, republicação de matérias veiculadas em outros sites, sendo que essa postagem pode vir replicada tal qual sua fonte original ou ser apresentada sob a forma de comentário crítico, resumo informativo, resenha. Dessa maneira, o blogue constitui-se principalmente com relação a sua arquitetônica, a que diz respeito à organização discursiva do conteúdo expresso pela matéria verbal, com base nas relações entre falante, objeto (tema) e ouvinte. Nos discursos da vida concreta, a forma composicional cria determinado discurso e a forma arquitetônica, uma determinada maneira de locução entre os parceiros da comunicação discursiva e o objeto (tema). Nas palavras de Sobral:

[...] a atividade do autor incide primordialmente sobre a forma arquitetônica, que é a organização do discurso, a partir da forma composicional, em termos de uma dada avaliação do discurso pelo autor e de sua recepção ativa por um ouvinte. A forma composicional se vincula com as formas da língua e com as estruturas textuais; a forma arquitetônica se vincula com o projeto enunciativo do autor, com o tipo de relação com o interlocutor que ele propõe. Por isso, a forma arquitetônica determina a forma da composição, mas esta nunca pode determinar a forma arquitetônica. Contudo, não há forma arquitetônica sem forma composicional, porque a organização arquitetônica precisa de um material no qual moldar o conteúdo. A forma arquitetônica, portanto, pode se realizar composicionalmente de várias maneiras (SOBRAL, 2010, p. 69).

É justamente a variedade de formas que caracteriza o estilo do gênero discursivo blogue que requer a esfera discursiva de onde ele emerge. $\mathrm{O}$ estilo está ligado ao enunciado e às formas típicas de enunciados (gêneros do discurso blogue caracterizado por todas as nuances de traços que qualificam cada gênero que aparece 
compondo-o). Assim, no que tange à estilística, temos um aspecto duplo, pois há o estilo individual e o estilo relativamente estável do gênero discursivo. Como o blogue pode ter diferentes tipos de registro, graus variados de formalidade, irá concatenar gêneros mais ou menos propícios para o estilo individual, uma vez que esse é um aspecto secundário do gênero, um epifenômeno, nas palavras de Bakhtin (p. 265-266).

$O$ estilo individual dá a dinamicidade do gênero porque é o arranjo do falante que possibilita ao gênero discursivo a sua singularização por meio da estilística que apresenta: em sua organização, na escolha das palavras, em tudo está a atitude valorativa do locutor em relação ao tema, à projeção do interlocutor, à orientação social.

O estilo, de modo geral, é inseparável de certas unidades temáticas e de certas unidades composicionais, acarretando em particulares tipos de acabamento, de acordo com a orientação social dos parceiros da comunicação discursiva; de suas relações interpessoais; da orientação para o outro, da situação em que se edifica, do tom que carrega.

Com o passar do tempo e a fixação de determinados blogues na internet, o espaço de publicação vai-se tornando mais específico. Às vezes, pelo grande número de visitas, de visualizações, o espaço pode ser ocupado por propagandas de empresas afins ao conteúdo das postagens, as quais buscam o público-alvo daquele site para promover suas marcas. Isso leva o blogue ao ramo profissional, deixando de ser uma atividade pessoal para ser compreendido como uma empresa.

É o que acontece, por exemplo, com blogues de opinião sobre produtos de beleza; blogues sobre viagem; gastronomia; e diferentes tipos de consultoria. Nessa proposta, os parceiros da interlocução assumem diferentes posições porque, muitas vezes, a empresa que "fala" e se manifesta nesse espaço virtual está disfarçada de consumidora comum que fala a um interlocutor comum e leigo como ela - são os chamados blogues patrocinados; essa já é outra forma composicional dentro da noção inicial do gênero discursivo blogue.

Os elementos que compõem os gêneros discursivos são aqueles que constituem todo discurso, a saber: conteúdo temático, construção composicional e estilo. O conteúdo temático envolve aquilo de que se fala: o tema. A estrutura composicional diz respeito às formas de organização e aos tipos de acabamento do discurso. O estilo, como explicado, divide-se entre o estilo característico de certas formas composicionais e o estilo que o autor emprega ao discurso, acomodando-o aos estilos, relativamente estáveis, que determinado gênero comporta.

O conteúdo temático está intimamente relacionado à forma de dizer e ao estilo. É certo também que todo tema edifica-se na relação dialógica que se dá entre locutor e interlocutor. A estrutura composicional, juntamente com o estilo, são também norteados por essa relação. Assim, sujeitos agentes produzem discursos acerca de determinados temas para interlocutores previamente pensados. A noção de alteridade perpassa essa relação e toda valoração que o discurso comporta edifica-se nessa composição eu-outro no que diz respeito a determinado tema.

Porque há no discurso a projeção de um interlocutor em relação a um tema é que se fala em endereçamento, que é uma orientação social do locutor para seu interlocutor; é o direcionamento que se dá ao discurso a partir da projeção de um tu. Em função desse traço, pode-se afirmar que o discurso em si contém a possibilidade de resposta, uma vez que conta com a atitude responsiva de outro sujeito agente situado em determinado esfera discursiva.

Como as noções bakhtinianas estão todas relacionadas, esse jogo social que vai formando o discurso na interação social a partir de relações dialógicas conta com o traço de valor que perpassa todos os atos do sujeito agente. Assim, os juízos de valor delineiam a própria relação eu-outro, edificando discursos em determinados tons. Afora essa axiologia consciente, existem as múltiplas vozes sociais dos mais variados campos de atuação humana que vão tecendo os discursos existentes na sociedade em que o sujeito está inserido.

Volochínov ([1926] 2010, p. 154-55) afirma que o discurso na vida não é autossuficiente, ele surge, pois, de uma situação extraverbal e com ela mantém vínculo. Assim sendo, as valorações que, por exemplo, as palavras do discurso carregam, independente do critério ético ou político que as norteie, envolve o aspecto verbal e a situação enunciativa extraverbal. Essas duas faces dão a totalidade da palavra, por isso, quando tomada isoladamente, como um fenômeno linguístico apenas, ela não pode ter juízo de valor porque está desassociada da vida que a completa. Os índices de valor são constituídos socialmente.

O contexto extraverbal que compõe a situação enunciativa apresenta três aspectos, a saber: o elemento espacial compartilhado pelos falantes, denominado como o horizonte espacial compartilhado; depois se tem o aspecto semântico, o tema ${ }^{5}$, isto é, o conhecimento e a compreensão comum da situação, e, por fim, o caráter axiológico, a valoração compartilhada, os juízos atribuídos. Esses três aspectos formam o subentendido que juntamente com o verbal constituem a totalidade enunciativa.

\footnotetext{
5 Que aqui se difere do tema do gênero discursivo. Tema, pois, na teoria bakhtiniana pode tomar duas expressões distintas: a) o caráter semântico pontual, dado pelo contexto enunciativo; o sentido da enunciação completa (BAKHTIN/VOLOCHÍNOV [1929] 2009, p. 133) e b) como um elemento constitutivo do gênero do discurso sendo entendido como aquilo de que se fala, o herói.
} 
Assim, no que tange à enunciação, explica Volochínov, sempre se têm participantes que igualmente conhecem, compreendem e avaliam a situação. Dessa maneira, "a enunciação se apóia em sua relação real e material a um mesmo fragmento da existência, atribuindo a esta comunidade material uma expressão ideológica e um desenvolvimento ideológico posterior" (p. 157). O autor explicita também que o aspecto extraverbal não é a causa externa da enunciação, nem algum tipo de força externa que sobre ela atua. A situação é parte necessária para a construção integral da composição semântica. Assim, o dito e o não dito compõem a enunciação.

A enunciação realiza-se, portanto, através do diálogo entre locutores e interlocutores, os quais unem uma significação a um tema - compreendem o aspecto linguístico em relação com sua expressão semântica dialógica, dinâmica e singular pontualmente constituída pelo momento enunciativo - e lhe atribuem um acento apreciativo, que carrega ideologicamente os signos e os atualiza no sistema linguístico, fazendo-o singular frente à situação enunciativa que o constitui. A interação entre elementos linguísticos, reiteráveis - o dado -, e a circunstância da enunciação, aspecto não reiterado - o novo - constrói os sentidos veiculados discursivamente e alimenta a cadeia da comunicação discursiva, apoiando-se em sentidos anteriores e projetando outros a partir de si.

Como o discurso, a enunciação é um fenômeno social resultante de relações dialógicas, isto é, relações que se estabelecem para além das noções do sistema linguístico porque se constituem discursivamente, comportam vozes sociais de interações outras e projetam enunciações futuras, alimentando a dinâmica da linguagem.

É por esse motivo que o conceito de signo é entendido como signo ideológico, implicando a compreensão de ideológico como axiológico. São os sentidos promovidos pela enunciação, que aliados ao aspecto linguístico, dão a valência do que é expresso na linguagem. Em Marxismo e Filosofia da Linguagem ([1929] 2009, p. 45) tem-se que os signos resultam de acordos sociais, de usos compartilhados e organizados pelos processos de interação concreta entre sujeitos agentes. Assim sendo, "as formas do signo são condicionadas tanto pela organização social de tais indivíduos como pelas condições em que a interação acontece. Uma modificação dessas formas ocasiona uma modificação do signo" (grifo do autor).

Essas afirmações demonstram o entendimento da dimensão social que circunscreve o signo e daí advém a necessidade de uma metodologia que não o separe de suas formas concretas de interação social nem separe a comunicação de sua base material (p. 45) porque são as mesmas condições que associam um elemento da realidade ao horizonte social que lhe dá expressão semiótica (p.47). Assim, forma - os elementos linguísticos, aqueles relacionados à significação - e tema - aspecto semânticosocial - constituem o signo ideológico, só podendo ser identificados separadamente com fins abstratos (p. 47).

É nesses termos que se pode compreender que a expressão do caráter emotivo-volitivo está inscrita na linguagem porque todo signo ideológico reflete e refrata, deixando entrever sua face reiterável junto aos índices de valor dialógicos, que expressam concordâncias ou discordâncias do embate de vozes sociais que o habita e o torna vivo e dinâmico. É justamente nesse sentido que se pode afirmar que não há discurso neutro.

As considerações precedentes discutiram alguns dos princípios teóricos desenvolvidos pelos pensadores do Círculo de Bakhtin que embasam a compreensão das reflexões desenvolvidas nesta pesquisa. Na sequência, encontrar-se-ão o material que compõe o corpus deste trabalho acompanhado de suas análises.

\section{Vozes em tensão: a constituição discursiva dos fatos sociais}

No ano de 2013, foram veiculadas postagens e notícias na internet sobre o embate entre um juiz e um político devido a uma charge de Carlos Latuff, cuja temática é a violência policial, conforme podemos visualizar na Figura 1. Dessas matérias, selecionaram-se três para realizar análises baseadas nos pressupostos teóricos de Bakhtin e seu Círculo de estudos, principalmente no que tange aos conceitos de gêneros do discurso, signo ideológico, relações dialógicas, discurso e valoração.

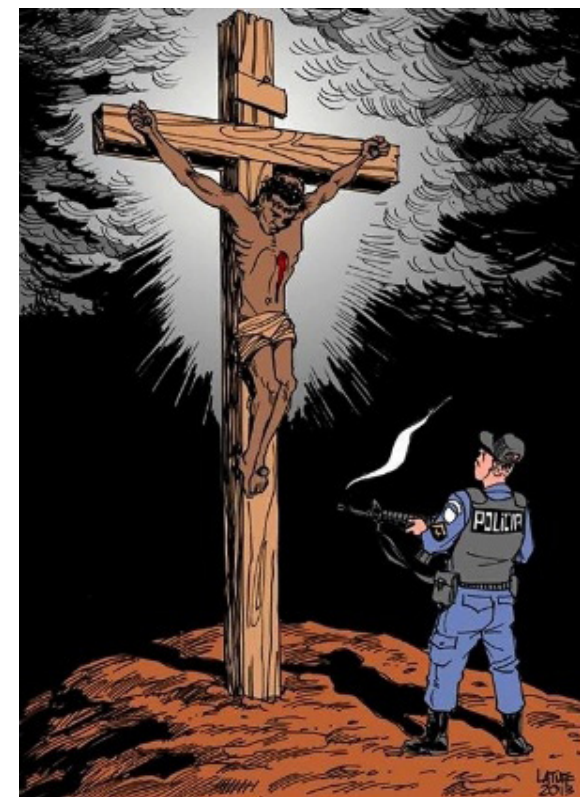

Figura 1. charge de Latuff, intitulada Por uma cultura de paz (2013).

Disponível em: <https://latuffcartoons.wordpress.com/2013/09/05/artigos-e-acharge-que-enfureceu-a-pm-e-tribunal-de-justica-do-rj/>. Acesso em: jun. 2015. 
Essa escolha deu-se em razão de as publicações terem diferentes perspectivas em torno do mesmo acontecimento, isto é, diferentes valorações acerca do mesmo objeto. A tonalidade das valorações pode ser apreendida por meio da matéria como um todo, sobretudo do excerto discursivo que lhe faz as vezes de manchete e convida o leitor ao texto, ademais de resumir o que será noticiado.

Com efeito, ao analisar três postagens de três bloques diferentes é possível perceber como se dá a construção discursiva dos fatos sociais - tomando como ponto de partida a noção de que toda enunciação implica valoração e, nesse sentido, o que há são construções apreciativas acerca dos fatos sociais.

Conforme é possível observar na Figura 2, a primeira postagem analisada apresenta o título "Charge de Latuff em gabinete de Juiz é censurada pelo TJ-RJ a pedido de Bolsonaro". No que tange ao aspecto linguístico, na manchete, há um jogo com a seleção do signo Bolsonaro, já que não há referente para esse sobrenome e o leitor pode relacioná-lo ao deputado federal Jair Bolsonaro, conhecido publicamente como uma pessoa polêmica - o que pode chamar à leitura. Apenas no texto da postagem é que o leitor fica sabendo que o referente para Bolsonaro é o filho do então deputado federal.

\section{Charge de Latuff em gabinete de Juiz é censurada pelo TJ-RJ a pedido de Bolsonaro}

O Órgão Especial do Tribunal de Justiça do Rio de Janeiro determinou um prazo até o meio-dia de hoje para a retirada da charge "Por uma cultura de paz" do gabinete do juiz João Batista Damasceno, da $1^{\text {a }}$ Vara de Órfãos e Sucessões.

A charge do cartunista Carlos Latuff está em um quadro e mostra um PM atirando, com um fuzil, em um homem negro crucificado.

O magistrado decidiu transferir a obra para a sala do desembargador Siro Darlan, pois lá a censura não tem efeito. $O$ desembargador diz que promoveu "asilo a uma obra de arte" e que "se alguém estiver insatisfeito que vá ao presidente do Superior Tribunal de Justiça reclamar".

O deputado estadual Flávio Bolsonaro (PP), que pediu a censura ao $\mathrm{TJ}$, vai encaminhar denúncia à corregedoria do tribunal.

Esse deputado, que é uma piada de mau gosto e é filho do deputado federal Jair Bolsonaro (PP), chegou a divulgar em seu site oficial um modelo de ação indenizatória para os policiais militares do Rio que se sentirem ofendidos com uma gravura do Latuff.

No Facebook, Latuff defendeu a livre exibição da charge e relatou supostas ameaças que teriam sido feitas por policiais militares, também na rede social, contra Damasceno. O magistrado afirmou que a obra evoca a violência do Estado contra o povo ao longo da história. Disse ainda que é favorável à desmilitarização da PM, pois "a política de segurança pública militarizada tem como alvo os pobres e excluídos, 'inimigos eternos' sujeitos ao extermínio".

Figura 2. Texto retirado de blog da internet. Disponível em: <http://blogdotarso.com/2013/09/04/charge-de-latuff-emgabinete-de-juiz-e-censurada-pelo-tj-rj-a-pedido-de-bolsonaro/>. Acesso em: jun. 2015.
Após a leitura do discurso inteiro (Figura 2), percebe-se que o aposto "que é uma piada de mau gosto e é filho do deputado federal Jair Bolsonaro (PP)" cria uma imagem negativa do deputado Bolsonaro ao explicitar que ele é filho de um político que rendeu ao parlamento muitas críticas. Essa construção dá-se na relação dialógica que coloca em questão todo o histórico de seu pai como uma personalidade pública controversa. Esse movimento requer do leitor acesso às vozes sociais que discorrem sobre as atitudes polêmicas que fazem da relação ser filho de um argumento contra o político que solicitou a censura ao tribunal de justiça.

Outra questão é que o excerto "Esse deputado, que é uma piada de mau gosto e é filho do deputado federal Jair Bolsonaro (PP)" está carregado negativamente por meio da analogia entre o gênero piada e a personalidade do parlamentar. Ao enunciar "Esse deputado, que é uma piada de mau gosto" o locutor realiza uma comparação que denigre a figura pública do político, uma vez que o descreve como nem mesmo digno de humor.

Além disso, o signo chegou, em "chegou a divulgar em seu site oficial um modelo de ação indenizatória para os policiais militares do Rio que se sentirem ofendidos com uma gravura do Latuff" tem o efeito de sentido também de valoração negativa do outro porque a palavra chegar imprime audácia frente à situação. Essa construção requer que o leitor acesse, em enunciados anteriores, uma imagem de indignação tamanha a ponto de fazer uma denuncia formal.

Conforme demonstrado, tudo que foi dito em relação a Bolsonaro apresenta explicitamente um juízo de valor negativo em relação ao político. Por outro lado, a partir do trecho " [...] Latuff defendeu a livre exibição da charge e relatou supostas ameaças que teriam sido feitas por policiais militares [...] contra Damasceno" não se pode dizer que o autor tenha sido a favor do chargista, já que em seu discurso faz uso da modalização, recurso utilizado em discursos que pretendem criar efeito de objetividade. Dessa maneira, discursivamente, por utilizar o advérbio "supostamente" e a construção verbal "teriam sido feitas" o locutor cria uma ação virtual, hipotética, caracterizando um efeito de afastamento dele para com os fatos narrados - no sentido de não comprometimento, de não tomar tais afirmações como verdadeiras.

Nessa construção, a mobilização de recursos linguísticos vinculados a padrões discursivos sociais fixados cria uma imagem imparcial, requerida, por exemplo, no discurso com intuito jornalístico, que preza pela aparente objetividade. Essa tentativa de neutralidade aponta o que Bakhtin/Volochínov ([1929] 2009, p. 32) diz: que não há discurso neutro, todos os signos são ideologicamente carregados, no sentido de serem atravessadas por apreciações valorativas. Propor-se neutro já é uma valoração. 
Nas postagens que foram comentadas, há relações de sentido instauradas entre os elementos verbais e não verbais utilizados para edificar o discurso veiculado em cada blogue. Ambas as linguagens imbricadas constituem o discurso expresso por quem o escreveu e deixam entrever a sua posição avaliativa. Ademais, a própria organização, a forma composicional, que dá sentido à forma arquitetônica, constrói, junto com a estilística, toda a valoração que perpassa esses discursos. Além disso, o fato de considerar o outro no momento da enunciação, isto é, por ter um público-alvo, o discurso toma forma de acordo com a orientação social desse auditório.

$\mathrm{Na}$ relação dialógica que se dá entre os discursos construídos nas postagens e os discursos que relataram anteriormente o fato social que tem como motivação a situação concreta que envolveu a polêmica da charge, compreende-se, pois, que os sentidos em circulação são produzidos a partir dos julgamentos de valor identificáveis ao longo de cada discurso. Antes mesmo de ler o texto, o leitor tem (ou pode ter caso esteja preparado para assim compreender a construção desse discurso em específico) o tom da matéria que será lida; ele consegue depreender o diálogo entre os fatos, as vozes sociais presentes em determinado discurso.

Nessa perspectiva, o foco não está no julgamento do fato concreto (vozes que anunciam que alguém ao ostentar uma obra mostra-se em concordância com seu valor social, bem como com as vozes que ela suscita, ao mesmo tempo em que alguém que reclama essa postura sinaliza sua oposição à situação), mas na construção discursiva dos personagens envolvidos nessa situação concreta: as postagens constituem discursivamente, pela organização estilística de seus enunciados, uma imagem positiva ou negativa dos sujeitos do discurso - muitas vezes deixando de descrever o fato em si.

De toda forma, pode-se perceber que o sujeito age valorativamente sobre os fatos sociais, tendo uma atitude responsiva frente aos discursos que circulam socialmente. Pode-se perceber também o quanto os discursos são ideologicamente carregados a partir de sua observação, atentando para sua forma composicional, seu conteúdo temático e estilo, bem como para a identificação das vozes sociais que suscitam para com elas entrar em consonância ou discordância.

As análises tiveram como intuito compreender o funcionamento do discurso a partir do entendimento das relações dialógicas que se dão para produzir efeitos de sentido que acarretam na construção discursiva dos fatos sociais. Assim, foi possível perceber que a linguagem é o fenômeno complexo que cria discursos que refletem e refratam o mundo, no sentido de que dão aos fatos sociais da vida concreta uma interpretação, sempre axiológica, do sujeito que enuncia.

É importante refletir sob essa abordagem da linguagem, uma vez que o leitor tem de estar atento aos mecanismos utilizados para persuadi-lo, bem como tenha a oportunidade de compreender que a linguagem não é neutra, por isso cada discurso diz mais do que aparenta, cada discurso traz em sua constituição vozes sociais que estão carregadas de valores. Dessa maneira, atividades de análise e reflexão como esta podem auxiliar no desenvolvimento das habilidades de leitura e compreensão de variados discursos.

\section{Considerações finais, mas não definitivas}

Com base nos pressupostos teóricos do Círculo de estudos de Bakhtin mencionados ao longo do texto, buscou-se analisar, à luz das noções de discurso, valor, signos ideológicos e vozes sociais, três postagens de blogues da internet que veicularam a notícia de um empasse entre um político e um juiz por conta da exposição de uma charge em local público.

Por meio da análise dos discursos propostos foi possível observar o funcionamento do discurso, sobretudo do gênero discursivo blogue, que a partir de relações dialógicas constitui-se ao redor de um tema, sob uma forma composicional, carregado semanticamente e tendo a projeção de um interlocutor. A noção de que o discurso está alicerçado no outro mostra a alteridade constitutiva como uma condição do discurso e dos sentidos em circulação.

Nessa perspectiva, o locutor de um discurso está sempre em tensão com vozes outras que o antecedem e o sucedem, dando reforço e estímulo para a produção dos mais variados discursos.

\section{Referências}

BAKHTIN, M. Gêneros do Discurso (1952-1953). In: BAKHTIN, M. Estética da Criação Verbal (1979). Trad. Paulo Bezerra. 6. ed. São Paulo: Martins Fontes, 2011.

BAKHTIN, M/VOLOCHÍNOV, V.N. Marxismo e filosofia da linguagem (1929). Trad. Michel Laud e Yara Frateschi. São Paulo: Hucitec, 2009.

BRAIT, Beth. Importância e necessidade da obra $O$ método formal nos estudos literários: introdução a uma poética sociológica. In: MEDVIÉDV, Pável. O método formal nos estudos literários: introdução a uma poética sociológica (1928). Trad. Sheila Camargo Grillo e Ekaterina Vólkova Américo. São Paulo: Contexto, 2012.

DI FANTI, Maria da Glória Corrêa. Discurso. In: FLORES, Valdir do Nascimento [et al.]. Dicionário de linguística da enunciação. São Paulo: Contexto, 2009. 
FARACO, Carlos Alberto. Linguagem e diálogo: as ideias linguísticas do Círculo de Bakhtin. São Paulo: Parábola, 2009.

SOBRAL, Adail. Do dialogismo ao gênero: as bases do pensamento do Círculo de Bakhtin. Campinas: Mercado de Letras, 2009.

VOLOCHÍNOV, V.A. a palavra na vida e na poesia. Introdução ao problema da poética sociológica (1926). In: BAKHTIN, M.
Palavra própria e palavra outra na sintaxe da enunciação. São Carlos: Pedro e João Editores, 2011.

Recebido: 25 de agosto de 2015

Aprovado: 03 de novembro de 2015

Contato: claudio.delanoy@pucrs.br tamiris.machado@acad.pucrs.br vanessa.barbosa@acad.pucrs.br 